\title{
The Optimal Regulation on Construction Industry in China*
}

\author{
Jiang Qifa \\ International Business School \\ Yunnan University of Finance and Economics \\ Kunming, China \\ fagenjiang3@163.com
}

\begin{abstract}
This paper aims to use the optimization theory to analyze the optimal regulation on Chinese construction industry, which is characterized by competitiveness, asymmetric information, and sophisticated regulation system. A model is constructed to prove the necessity of keeping the Minimum Quality Standard (MQS) and illustrate the optimal regulation. After discussing the disadvantages of MQS, suggestions how to enforce the optimal regulation are put forward, e.g. less intervention, heavy penalty to firms which do not meet the construction regulation, further reform, etc.
\end{abstract}

Keywords-Optimization, Construction Regulation, Minimum Quality Standard (MQS)

\section{INTRODUCTION}

Regulations by governments will be high costly. As a competitive industry, construction has been implemented many regulations and the regulation system is fairly sophisticated in China [1]. Therefore, Chinese people will argue the following questions, e.g. why should governments enforce so many regulations on construction industry? How should we analyze the benefits and costs from regulations? Is it a prerequisite of promoting the development of industry for so many regulations and sophisticated system? And, if we want to develop the industry, which condition will be optimal to maximize the social welfare? In this paper we try to use the optimization theory to examine the effects of rules and regulations, and find out the optimal regulation for Chinese construction industry.

\section{LITERATURE REVIEW}

\section{A. Reviews on regulations for competitive industries}

In a free market, there is little regulation by governments, which was early discussed by Adam Smith [2]. Commonly there are four reasons resulting in market failure thus governments will intervene in the free market: 1 . monopoly or market power; 2 . public goods; 3 . externalities; 4 . asymmetric information [3].

The reasons that governments will intervene in the competitive market might be asymmetric information and externalities. Asymmetric information will induce the Lemmon Market, and then reduce the social welfare [4].
Externalities can be classified into negative and positive externality groups, such as pollution and innovation, which can be corrected by pollution tax and intellectual property respectively [5].

Regulations can be categorized into two groups: economic and social regulations. The former refer to rules or controlling activities impacting on the firm's decision of market entry, price and quantity or sorts of product; the latter refer to rules, which aim to protect consumers, labors and the public and mainly focus on occupational health, working place safety, and environmental protection (HSE). Actually, in competitive industries, social regulations are more popular than economic regulations [6].

\section{B. Reviews on Chinese Construction Regulations}

Regulations and rules on Chinese construction involves almost any aspect of industry, including pricing, products (kinds and outputs), bidding and tendering, operation and designing, and even issues on project management such as scheduling, risk management, cost controlling, etc. Another special kind of regulation is technical standard, there are up to 5,000 technical standards in the industry. In China these standards are issued by governments and regarded as a kind of technical rules, especially for mandatory standards [7], other than in developed countries where standards are mainly issued by professional associations and adopted voluntarily by firms.

Other characteristics of regulations include [8]:

1) Sophisticated administration: In China there are about 24 departments, including the Department of Construction, directly related to the administration of the industry.

2) Complex system of law and statute: About 5-6 levels regulations are implemented for Chinese construction.

3) Many style and kinds of form and content: More economic than social regulations are enforced, including (but not limit to):

a) Approval of construction, qualification, bidding and tendering, etc.

b) Recording of awards, project completion, etc.

c) Examination of construction market, quality and safety, implementation of construction laws and rules, etc. 
d) Administrative penalty and sanction: Correction, shutdown, suspension, lowering and revocation of qualification, penalties, confiscating, compensating, and tracing legal responsibility, etc.

\section{4) Poor law enforcement:}

For Chinese construction regulation, governments focus more on making law; however, less attention is paid to its execution.

On the whole, the Chinese construction administration is marked by overstaffing, organizational overlapping, complicated procedures and extremely low efficiency [9]. Results from the administration have shown that over and under regulation co-exist in Chinese construction industry nowadays [10]. Therefore, in order to reduce the regulation cost and develop the industry, optimal regulation should be analyzed.

\section{THE MODEL}

Based on the discussion of implementing a minimum quality standard (MQS), we then can prove the optimal quality regulation on construction industry.

\section{A. The Minimum Quality Standard (MQS)}

From a quality regulation perspective, the rationale of regulations can be analyzed more carefully.

When a firm wants to produce some products, it is critical to decide which level quality in a Product Space, which means a spectrum of quality from low to high quality [11]. This decision will impact greatly on the firm's profit, therefore how to choose the product quality is a strategic decision and there exists an optimal quality to maximize its profit for a firm [12].

On the other hand, from the demand side, consumers are heterogeneous and form a differentiated Hotelling model from low to high quality [13]. There exists an optimal quality to maximize the social welfare.

As indicated above, the Lemon Market, resulting from asymmetric information, will reduce the social welfare. Thus it is necessary to set a minimum product quality standard by governments [14].

Suppose that a construction firm will produce a kind of accessory, potential sellers and buyers are $N(N$ is plentiful enough). Sellers and Buyers are rational and risk neutral. In a competitive market, the prices of the products sold by sellers are the same.

Suppose that the sellers' quality distribution function is $F(s)$, and its density function is $f(s), s \in\left[s_{\min }, s_{\max }\right]$. When the accessories are used by the firms themselves with the s quality, all sellers keep the same surplus $\left\{\theta_{0} \cdot s\right\}$; and when the accessories are sold out, the firms will benefit from the market price, $p$ (all the sellers benefit identically except for the quality costs). The buyers are heterogeneous, $\theta \in\left[\theta_{\min }, \theta_{\max }\right]$, the distribution function is $G(\theta)$, the density function is $g(\theta)$. Therefore the utility of sellers, $U^{s}$ and the utility of buyers, $U^{b}$, are the following:

$$
\begin{gathered}
U^{s}=\left\{\begin{array}{l}
p, \text { if the trade is successful. } \\
\theta_{0} \cdot s, \text { if the trade is failed. }
\end{array}\right. \\
U^{b}=\left\{\begin{array}{l}
\theta_{0} \cdot s-p, \text { if the trade is successful. } \\
0, \text { if the trade is failed. }
\end{array}\right.
\end{gathered}
$$

Therefore, the sellers' feasible product space is $s^{f} \in\left[0, p / \theta_{0}\right]$, and the buyers' expected quality is $s^{a}(p)=p / 2 \theta_{0}$. The trade will be successful only when $\theta>\theta_{0}$ in the condition of symmetric information, the effective volume of business is

$$
D^{*}(p)=N \cdot\left[1-G\left(\theta_{0}\right)\right]
$$

And the trade will occur only when $\theta \cdot s^{a} \geq p$, thus the volume of business is

$$
D(p)=N \cdot\left\{1-G\left[p / s^{a}(p)^{3}\right]\right\}
$$

The quantity of sellers is

$$
O(p)=N \cdot F\left(p / \theta_{0}\right)
$$

Suppose that $\mathrm{f}$ and $\mathrm{g}$ are the uniform distributions between $[0,1]$, then when the market is equilibrium, $O(p)=D(P)$, which means that the quantity of demand is equal to the quantity of supply, thus:

$$
\begin{gathered}
O^{0}(p)=N \cdot p / \theta_{0} \\
s^{a}(p)=p / 2 \theta_{0} \\
D^{0}(P)=N \cdot\left(1-2 \theta_{0}\right)
\end{gathered}
$$

When $\theta_{0} \geq 1 / 2$, the trade will not occur; when $\theta_{0} \leq 1 / 2$, there exists the only competitive equilibrium price $p^{0}=\theta_{0}-2 \theta_{0}^{2}$. The volume of business is

$$
D^{0}=N \cdot\left(1-2 \theta_{0}\right)<D^{*}=N \cdot\left(1-\theta_{0}\right)
$$

The formula (9) demonstrates that the trade will reduce under the condition of asymmetric information contrasting with symmetric information.

- Proposition 1: Under the conditions of asymmetric information, the trade will reduce and therefore this condition makes against the market and social welfare.

Suppose that the government sets a minimum standard $s_{0}$, hereby the buyers' expected quality level will be

$$
s^{a}(p)=\left(\frac{p}{\theta_{0}}+s_{0}\right) / 2
$$

The quantity of sellers' product will be

$$
O(p)=N \cdot\left(\frac{p}{\theta_{0}}-s_{0}\right)
$$

The quantity of buyers' demand will be

$$
D(p)=N \cdot\left[1-\frac{p}{s^{a}(p)}\right]
$$


Suppose $\theta_{0}=1 / 2$, if $s_{0}=0$, the trade will not occur. Only when $_{S_{0}}>0$, there exists the equilibrium price

$$
p^{c}=\frac{1}{2} \sqrt{s_{0}+s_{0}^{2}}
$$

Therefore, implementing a minimum quality standard (MQS) will promote the social welfare.

- Proposition 2: If the government will implement the Minimum Quality Standard (MQS), the trade will be benefited from MQS and the social welfare will be promoted.

\section{B. The Optimal Regulation on Asymmetric Information Construction Industry}

The above discussion is concentrated on the firm's side, e.g. on how to maximize the enterprise's profit. To maximize the social welfare, which is the optimal regulation level?

Suppose there is a benevolent social planner who will maximize the social welfare, e.g.

$$
\begin{aligned}
& U=\operatorname{Max}\left(\Delta U^{s}+\Delta U^{b}\right) \\
& \text { s.t. } \theta=\theta_{0}
\end{aligned}
$$

And then,

$$
U=\operatorname{Max}\left\{\left(p-\theta_{0} \cdot s\right) \cdot N \cdot \frac{p}{\theta_{0}}+(\theta \cdot s-p) \cdot N \cdot\left(1-2 \theta_{0}\right)\right\}
$$

Respectively required for partial derivatives of $p$ and $s$, $\partial U / \partial p, \partial U / \partial s$, we get the results

$$
p^{*}=\theta_{0}-2 \theta_{0}^{2}=p^{0}
$$

It is evident that, in the condition of asymmetric information, competitive equilibrium will result in the maximization of social welfare.

- Proposition 3: Under the conditions of asymmetric information, if the market is competitive and runs well, or the government intervenes effectively in the market and makes it work well, e.g. the market price indicates the quality of products, then the optimal quality selected by the market in the manufacturing process of a firm will be the optimal quality necessary for the society.

\section{DISCUSSION}

There is no such thing as a free lunch. The Minimum Quality Standard (MQS) will benefit the trade and society, however, is there any disadvantage for MQS? The answer might be "yes". The following section we will discuss two issues on the disadvantages of MQS.

\section{A. Effects of MQS on the Consumers' Choice}

For a static market, because of the existence of MQS, firms will produce less sorts of product; therefore the consumers' choice will reduce [15]. As shown beneath the figure (see Fig. 1), suppose that the product quality follows the uniform distributions between $[0,1]$, a product quality stands for a kind of product. When implementing MQS and improving the product quality, it means that we set $M Q S>0$, and shift MQS from left side to right side in the Product Space. From Fig.1, we can conclude that the sorts of product will reduce though quality will be higher (if all firms will conform to MQS), hence the consumers' choice will decrease.

\section{Level of MQS}

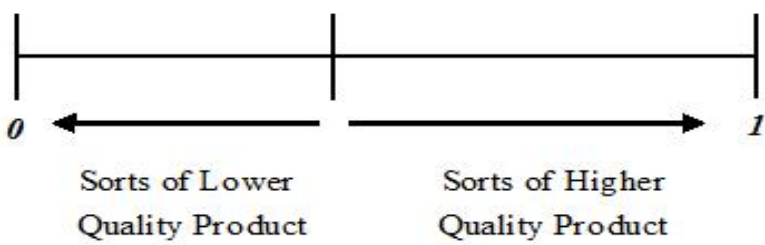

Fig. 1. MQS and the Product Space

- Proposition 4: If governments set higher MQS, then the product quality will increase; however, in this condition the consumers' choice of goods varieties will probably decrease. Because MQS can promote the social welfare, therefore, governments should balance economic performance against consumers' choice.

\section{B. Effects of MQS on the social costs of products}

Another important thing is that, with the improvement of quality, the cost of product will increase, too. Thus, the social cost will add up in pace with the implementation of MQS enforced by governments.

Generally, because of the Law of Diminishing Return, to a firm the cost curve of quality, $C(q)$, is convex, e.g. its firstorder derivative, $M C>0$, and its second-order derivative, $M C^{\prime} \geq 0$; and the revenue curve of quality, $R(q)$, is concave, e.g. its first-order derivative, $M R>0$, and its second-order derivative, $M R^{\prime} \leq 0$.

As shown beneath the figure (see Fig. 2), the profit from the product quality, $P(q)=R(q)-C(q)$, and the optimal quality of a firm exists the point $Q^{*}$, where $P^{\prime}(q)=R^{\prime}(q)-C^{\prime}(q)=0$, which means $M R(q)=M C(q)$.

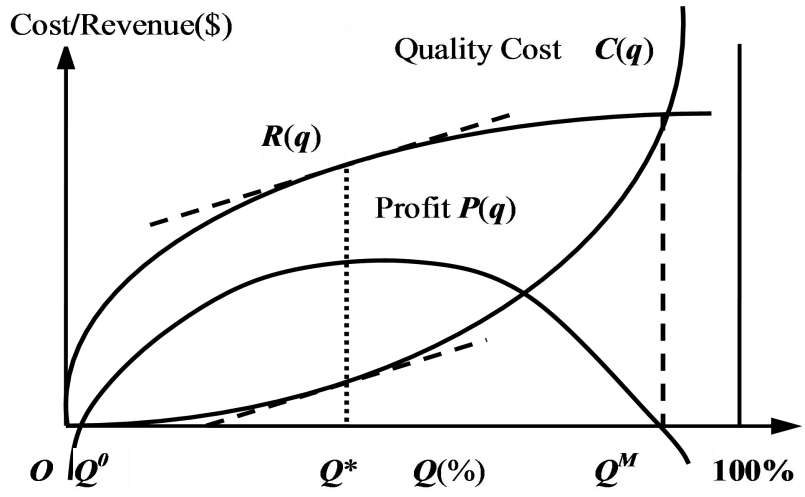

Fig. 2. The Optimal Quality of a Firm 
When governments set a higher quality standard, $Q_{M}>Q^{*}$, it is disadvantageous to firms because the profit will be smaller at this point. A higher MQS will increase the cost of product, and the consumers and firms will bear the cost. When MQS is larger than $Q^{*}$, the cost will be too high to the society; and in this situation, the higher MQS, the more unfavorable to the society because of the decreasing of profit, and at last the cost will be more than revenue so that the profit will be negative. Therefore, governments should choose an optimal regulation for product quality.

- Proposition 5: Under the given technical and economic circumstances, there exists an optimal regulation, $Q^{*}$. When governments set a lower quality standard, e.g. $M Q S<Q^{*}$, it is disadvantageous to the society because social welfare does not come to the maximum; when governments set a higher quality standard, e.g. $M Q S>Q^{*}$, it is also disadvantageous to the society, at this point the social cost will be so high that social resources will be overused and firms and consumers will increasingly suffer costs, hence the social welfare will be at a loss.

\section{CONCLUSIONS AND SUGGESTIONS}

\section{A. Conclusions}

For a competitive industry, e.g. construction industry, because of asymmetric information, the market condition will reduce the social welfare; and if governments enforce MQS, the trade and social welfare will benefit from MQS. If the market runs well, the optimal quality selected by the market will be the optimal quality necessary for the society.

MQS will probably decrease the consumers' choice of various goods; and if governments increase MQS, the social cost of product will also grow, hence governments should select an optimal regulation of MQS for product quality.

\section{B. Suggestions}

From the above analysis, we can come to the conclusion that it is necessary for the government to intervene in the competitive industry because of asymmetric information; however, it is a difficult thing for intervention because suitable action is not effortless and incorrect action will be highly costly. Thus, in order to enforce the optimal regulation on Chinese construction industry, suggestions are as follows:

\section{1) Suggestion 1:}

Regulation and intervention will cost highly and are difficult to find the suitable way. Thus except for MQS, governments should not intervene in the market so much. The basic function of government is to guarantee good work of the market.

\section{2) Suggestion 2:}

Firms should be penalized more severely because of not meeting regulations enforced by governments. When implementing regulations the most important thing is that enterprises must conform to MQS and other regulations. However, in China poor law enforcement will erode the effect _of regulations. It might be one of the most important things for Chinese construction regulation to be sure to have good effectiveness and authority.

\section{3) Suggestion 3:}

Governments should gradually decrease the number of state-owned enterprises (SOEs), and reform in deregulation and privatization should be continued. As being a competitive industry, private firms should be the basic entities for construction market. Often conducting in the market by governments instructions, SOEs generally make discretionary decision with difficulty and response slowly. We can argue that intervention is too much just because there are so many SOEs in the industry. Thus, it is necessary to reduce the number of SOEs in this industry.

\section{ACKNOWLEDGMENT}

This work is supported by National Natural Science Foundation of China (NSFC) under Grant 71463061 (Project Title: Study on Participatory Appraisal Mechanism for Local Government Public Works).

\section{REFERENCE}

[1] Q.F. Jiang, "Study on Impacts of Regulations on the Development of Construction Industry (in Chinese)," Zhongnan University of Economics and Law Doctorate Dissertation, 2009, pp. 10-12.

[2] Adam Smith, "An Inquiry into the Nature and Causes of the Wealth of Nations," London: The Electric Book Co, 1998.

[3] N. Gregory Mankiw, "Principles of Economics," Cincinnati OH: SouthWestern College Pub, 2006, pp. 11-12.

[4] G.A. Akerlof, “The Market for 'Lemons': Quality Uncertainty and the Market Mechanism,” The Quarterly Journal of Economics, vol. 84, 1970 pp. 488-500.

[5] Paul A. Samuelson, William D. Nordhaus, "Economics," New York: McGraw Hill Higher Education, 1999, pp. 19.

[6] Q.Z. Chen, "The Theory of Governmental Social Regulation and the Application Research (in Chinese)," Beijing: The Economic Science Press, 2008, pp. 10-20.

[7] L.I. Shirong, "The Status and Function of Standardization in Modern Market Economy (in Chinese)," China Standardization, 2003, pp. 22-25.

[8] Q.F. Jiang, "Regulations on Construction: Theory, Practice and Industrial Development (in Chinese)," Beijing: Economic Science Press, 2011, pp. 73-78.

[9] Q.F. Jiang, "Study on Reforming and Improvement in China's Construction Regulation System (in Chinese)," Construction Economy, 2001, pp. 12-15.

[10] L.I. Jian, "Research on the Government Regulations of Chinese Construction Industry (in Chinese)," Jilin University Doctorate Dissertation, 2009, pp. 10-12.

[11] J. Tirole, “The Theory of Industrial Organization. Cambridge," MA: The MIT Press, 1988, pp. 20-40.

[12] Z. Zhong, F.H. Lei, T.S. Liu, "Study on General Framework of Quality Economics-Also on the New Connotation of Food Quality and Safety [in Chinese]," Soft Science, vol. 27, 2013, pp. 69-72.

[13] H. Hotelling, "Stability in Competition," Economic Journal, vol. 39, 1929, pp. 41-57.

[14] C. Wilson. "The Nature of Equilibrium in Markets with Adverse Selection. Bell Journal of Economics," vol. 11, 1980, pp. 108-130.

[15] J. Farrell, and G. Saloner. "Standardization and Variety," Economics Letters, vol. 20, 1986, pp. 70-74 
[16] Q.F. Jiang, "Study on Performance Evaluation of Standardization Strategy for Construction Enterprises (in Chinese)," Wuhan University Doctorate Dissertation, 2013, pp. 181-183. 